\title{
Compressive Strength and Elastic Modulus of Slurry Infiltrated Fiber Concrete (SIFCON) at High Temperature
}

\author{
Ali Mudhafar Hashim ${ }^{\text {a }}$, Mohammed Mansour Kadhum ${ }^{\text {a* }}$ \\ ${ }^{a}$ Department of Civil Engineering, College of Engineering, University of Babylon, Babylon, Iraq.
}

Received 10 October 2019; Accepted 29 December 2019

\begin{abstract}
SIFCON is a special type of fiber reinforced concrete (FRC) with an unattached fiber matrix that gives the composite matrix important tensile properties and, due to its high fiber content, SIFCON also has distinctive and unique ductility and energy absorption properties. Higher temperature resistance is one of the most important parameters affecting the durability and service life of the material. In this research, the compression strength and elastic modulus of Slurry Infiltrated Fiber Concrete (SIFCON) were tested both before and after exposure to high temperatures. Two fire exposure durations of 2 and 3 hours are examined. In addition to room temperatures, three temperature ranges of $400{ }^{\circ} \mathrm{C}, 600^{\circ} \mathrm{C}$ and $900{ }^{\circ} \mathrm{C}$ have been introduced. The results of the experiment showed that the compressive strength and elastic modulus decreased after exposure to high temperatures. The drastically reduction of compressive strength took place with increasing temperature above $600{ }^{\circ} \mathrm{C}$. While, the reduction in elastic modulus values is more significant than the decrease in compressive strength at the same fire flame temperatures. The residual compressive strength and elastic modulus at $900{ }^{\circ} \mathrm{C}$ were in the range of $(52.1 \%$ to $59.6 \%)$ and $(30.6 \%$ to $34.1 \%)$ respectively.
\end{abstract}

Keywords: SIFCON; Steel Fiber; Fire; Elastic Modulus; Compressive Strength.

\section{Introduction}

Slurry infiltrated fiber concrete (SIFCON) was initially developed in 1979 by Lankard Materials Laboratory, Columbus, Ohio, USA, by incorporating large quantities of steel fibers into reinforced cement composites [1]. SIFCON can be considered as a special type of fiber reinforced concrete (FRC) with a high fiber content where the fibers are molded and infiltrated with cement-based slurry or flowing mortar. Despite the high cost of SIFCON, it is more widely used throughout the world, especially in explosive and impact structures. This is because most of the mechanical and durability properties of these materials are better than those of conventional FRC [2]. SIFCON has a very good application potential in an areas where impact resistance and high ductility are required, especially in the design of the seismic retrofit, in the structures under impact and explosive effects and in the repair of the reinforced concrete structural element. In general, the conventional fiber reinforced concrete (FRC) contains fibers (1-3) \% by volume, whereas (SIFCON) contains (4-20) \% of fibers. Even though the current practical ranges from (4 to 12) \% [3]. SIFCON matrix is a cement slurry or flowing mortar different from the aggregate concrete used in FRC. Thus, SIFCON's production varies from FRC, which is produced by adding fibers to the fresh concrete, while SIFCON is produced by infiltrating a bed of pre-placed fibers with cement slurry and tightly packed in the mold [2, 4].

The mechanical properties of SIFCON members are evaluated by Shanthini and Mohanraj [4]. The cement-based slurry used was a mixture of different percentages of cement, fly ash, silica fume and eco sand to soil. In this study, the

* Corresponding author: drmohalkafaji@gmail.com

http://dx.doi.org/10.28991/cej-2020-03091469

(C) 2019 by the authors. Licensee C.E.J, Tehran, Iran. This article is an open access article distributed under the terms and conditions of the Creative Commons Attribution (CC-BY) license (http://creativecommons.org/licenses/by/4.0/). 
water cement ratio of 0.5 and super plasticizer was adopted $2 \%$ by weight of cement. The $8 \%$ fiber content by volume implemented for SIFCON, distributed randomly. The compressive and splitting tensile strength test results after 28 days of curing were $(68.5,65,66.5) \mathrm{MPa}$ and $(9.86,9.2,8.87) \mathrm{MPa}$, respectively, for the three slurry mix ratio. The researchers found that the members of SIFCON are much better than conventional concrete.

Salih, Frayyeh et al. [5] study the effect of hooked ended steel fiber content and mineral admixture replacement silica fume (SF) on strength and deformation characteristics of SIFCON specimens under flexural loading. In this investigation, three volume fractions of steel fiber $(6,8.5$, and 11) percent were used. The amount of SF replacement in SIFCON slurry was (10 percent) by weight of cement. Monitoring samples of $100 * 100 * 400 \mathrm{~mm}$ at the age of 7 and 28 days carried out both the flexural strength and toughness characteristic. The findings of these experiments were compared as control samples with those conducted on standard fiber-reinforced mortar (FRM) with 2 percent fiber content. The test results indicate superior properties of SIFCON, as compared to normal FRM, which was positively affected by the use of cement materials (SF) as a partial substitute by cement weight and by increasing the steel fiber volume fraction. The value of flexural strength and toughness up to (28.08 MPa) and (159 N.mm) was obtained at 28 days of age respectively.

The inclusion of steel fibers in concrete has been recognized as a means of improving cracking resistance. Over the past three decades, steel fiber has increasingly been used to enhance refractory concrete performance in many applications as it extends service life. Fiber was widely used to improve concrete ductility. The ability of steel fibers has been shown particularly, to enhance the resistance of spalling of refractory concrete [6]. It is therefore recognized that steel fibers could help enhance the fire efficiency of SIFCON components by delaying concrete spalling. Thus indirectly helping to confinement concrete under compression load [7]. Therefore, it is proposed to conduct an experimental investigation to study the behavior of SIFCON samples at high temperatures.

Khaliq and Kodur [8], examine the effect of temperature on self-consolidating concrete (SCC) and fiber-reinforced SCC (FRSCC) thermal and mechanical properties. Specific heat, thermal conductivity and thermal expansion were measured for thermal properties, whereas compressive strength, tensile strength and elastic modulus were measured for mechanical properties in the $20-800^{\circ} \mathrm{C}$ temperature range. The test program considered four SCC mixes, SCC plain, steel, polypropylene, and SCC reinforced hybrid fiber. Results from mechanical property tests show that steel fibers improve the splitting tensile strength at high temperature and the SCC elastic module FRSCC thermal expansion is also slightly higher than SCC thermal expansion at a range of $20-1000{ }^{\circ} \mathrm{C}$.

Beglarigale, Yalçınkaya et al. [9] studied SIFCON's high-temperature composite flexural performance. The scope of this research was subjected to normal or steam cured slurry infiltrated fiber concrete (SIFCON) and slurry samples at 300, 600, 750 and $900{ }^{\circ} \mathrm{C}$. Exposing the samples to $300{ }^{\circ} \mathrm{C}$ improved mechanical performance whereas higher temperatures have detrimental effects on SIFCON composites such as loss in the steel fibers cross section and degradation of $\mathrm{C}-\mathrm{S}-\mathrm{H}$ structure.

Exposure to high temperatures, mainly caused by accidental fires, is one of the most severe conditions for building and structural damage. The fire resistance and post-heat exposure behavior of the structural component depends on the thermal and mechanical properties of the composite materials. Elasticity is one of the important material properties that play an important role in the structural behavior of concrete elements both before and after exposure to elevated temperatures [10]. For reasons such as fire or explosion, SIFCON used to strengthen work and military systems may be exposed to high temperatures. High temperature exposure is one of the most important physical degradation processes affecting the life of cement-based composites [9]. Since SIFCON is a relatively new building material, little information on the characteristics of SIFCON is known from previous studies. From this point of view. The primary objective of this research is to perform an experimental investigation to study the effect of fire exposure on the compressive strength and elastic modulus of SIFCON samples after high temperature exposure. The authors believe that this detail study dealing with the performance of slurry infiltrated fiber concrete (SIFCON) samples exposed to direct fire flame is carried out for the first time and will be very useful to concrete technology.

\section{Materials and Mix Proportions}

A variety of trail slurry mixtures have been used to find an appropriate mixture with optimal characteristics in terms of viscosity, fluidity and filling ability without bleeding or segregation or honeycombing in the fiber network, which causes a dramatic reduction in the mechanical properties of SIFCON. The properties of the mixture are shown in Table 1. Workability of SIFCON slurry is determined by the mini-slump flow test with accordance to ASTM C1437-15 as $260 \mathrm{~mm}$. Viscosity of the slurry is also assess by Mini V-funnel test and the time measured was $11 \mathrm{~s}$. The overall experimental investigation is shown in the flowchart given in Figure 1.

The physical, chemical and mechanical properties of ordinary Portland cement (OPC) Type I which complies with the ASTM C150-18 specification, used in this investigation are listed in Table 2. The silica fume (SF) utilized in this investigation conforms to the ASTM C1240-15 requirements, and the chemical compositions of it are also given in 
Table 2. Fine sand with a maximum size of $1.18 \mathrm{~mm}$ and specific gravity of 2.60 is used as fine aggregate for SIFCON. It must be small enough to achieve full infiltration without clogging through the dense steel fiber. Figure 2 shows the grading curve of the natural sand.

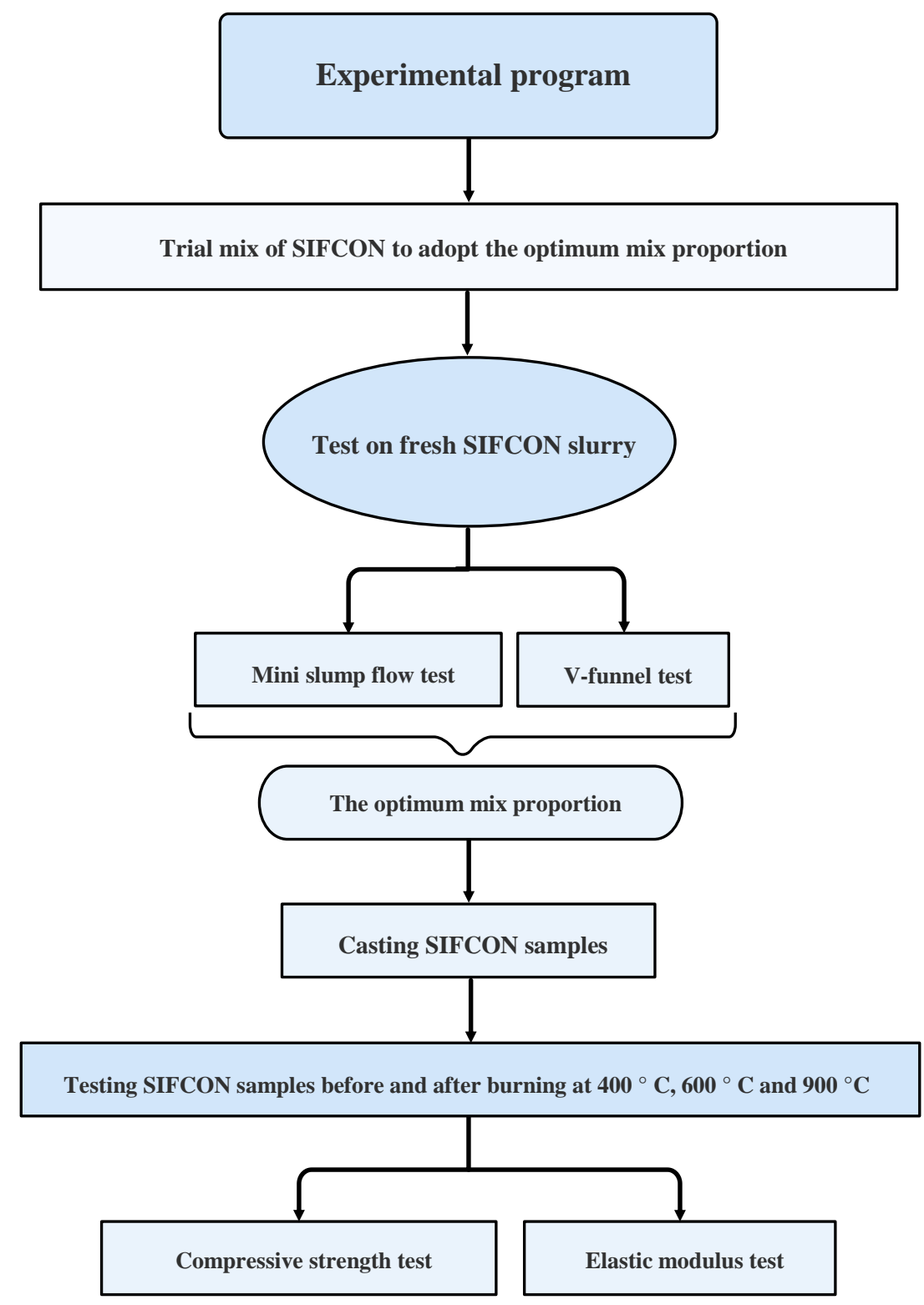

Figure 1. Flow chart of the research plan

Table 1. Mix design for SIFCON matrix

\begin{tabular}{cc}
\hline Composition Type & Mix Proportion \\
\hline Cement & $872.4\left(\mathrm{~kg} / \mathrm{m}^{3}\right)$ \\
SF & $96.9\left(\mathrm{~kg} / \mathrm{m}^{3}\right)$ \\
Sand & $969\left(\mathrm{~kg} / \mathrm{m}^{3}\right)$ \\
Steel Fibre & $468\left(\mathrm{~kg} / \mathrm{m}^{3}\right)$ \\
(SP) by the Weight of Cementitious & $3.7(\%)$ \\
Water/binding & 0.33 \\
Mini-slump flow & $260(\mathrm{~mm})$ \\
V-funnel time & $11(\mathrm{~s})$ \\
\hline
\end{tabular}




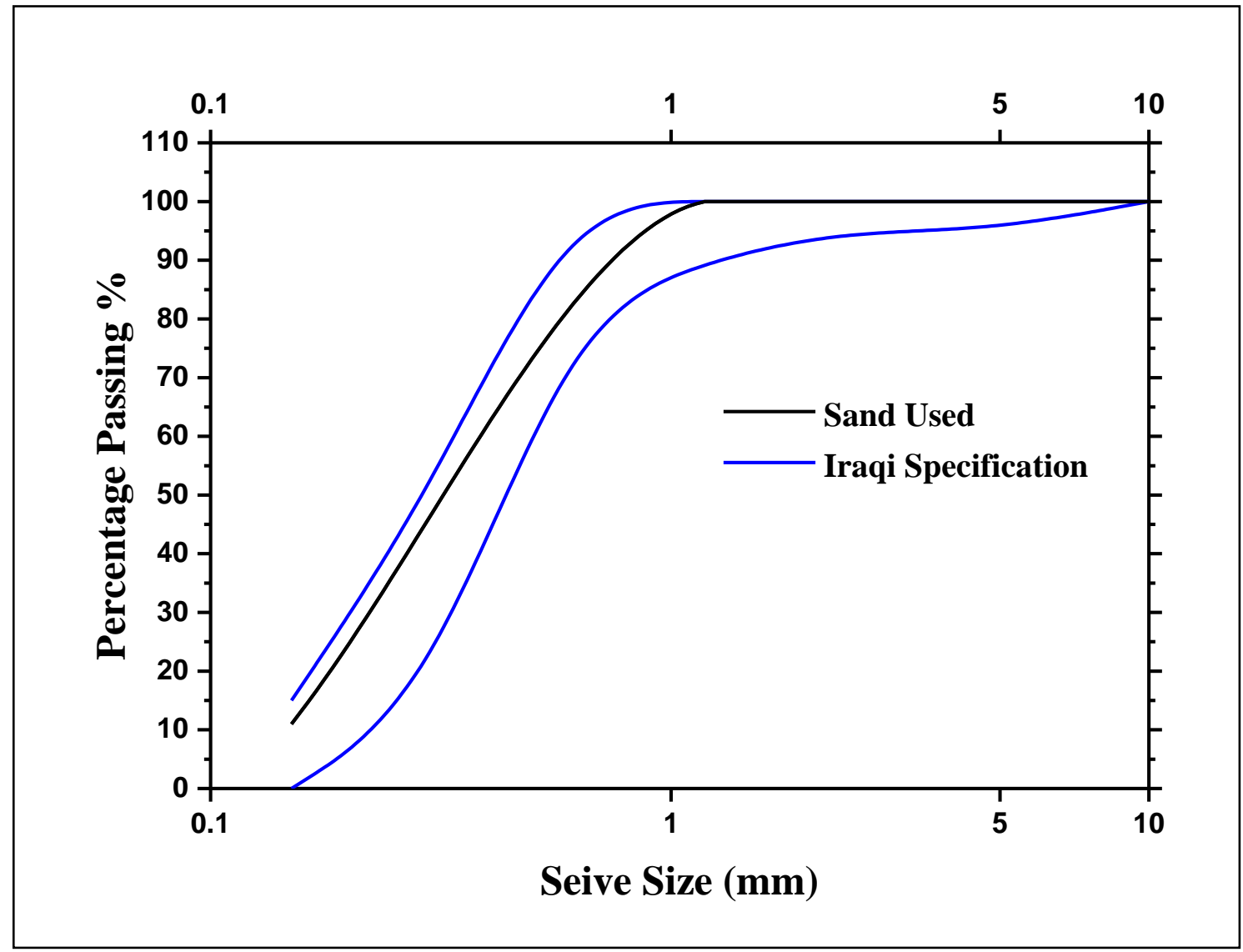

Figure 2. The grading curve of the original sand

In order to achieve the desired slurry workability, a polycarboxylate super plasticizer (SP) type which conforms to ASTMC494/C494M-17 was added to the mixture to ensure the passing of it through the fiber network without leave honeycombs, where the SP makes it sufficiently liquefied. In addition, two types of steel fiber, which differ in shape and aspect ratio, were used in this research. The first type was hooked end steel fibers with $(0.5 \mathrm{~mm})$ diameter, $(30 \mathrm{~mm})$ length, and a 60 aspect ratio with a tensile strength greater than $1100 \mathrm{MPa}$. The second type was straight steel fiber (micro steel fiber) having length of $(13 \mathrm{~mm})$, diameter $(0.2 \mathrm{~mm})$, and above 2,500 MPa tensile strength with 65 aspect ratio. Volume fraction of steel fiber $(\mathrm{Vf})$ used in this study was $6 \%$ (3\% hooked end steel fiber and $3 \%$ micro steel fiber). Fibre volume was calculated according to the volume of the mold for each specimen. Figure 3 illustrate the micro steel fibers and hooked end steel fiber used in this study.

The compression strength (fcu) test was performed using $(100 \times 100 \times 100) \mathrm{mm}$ cubes in compliance with ASTM C 109/C 109M. While the static modulus of elasticity was carried out in accordance with ASTM C469-87 and using cylinders with a length of $200 \mathrm{~mm}$ and a diameter of $100 \mathrm{~mm}$. The mortar must be sufficiently flowable to ensure penetration through the fiber as shown in Figure 4. After casting, samples were demolded after keeping it at $20 \pm 2{ }^{\circ} \mathrm{C}$ for $24 \mathrm{~h}$ in saturated humid air. The samples have been cured in water for 28 days with $20 \pm 2{ }^{\circ} \mathrm{C}$ water curing temperature.

Table 2. Chemical, Physical and mechanical properties for cement and silica fume

\begin{tabular}{|c|c|c|c|c|}
\hline Chemical composition (\%) & Cement & Silica Fume (SF) & Physical properties & \\
\hline $\mathrm{SiO} 2$ & 65.0 & 89.41 & Cement & \\
\hline $\mathrm{A} 12 \mathrm{O} 3$ & 20.6 & 0.63 & Specific gravity & 3.15 \\
\hline $\mathrm{Fe} 2 \mathrm{O} 3$ & 3.7 & 0.45 & Specific surface $\left(\mathrm{m}^{2} / \mathrm{kg}\right)$ & 326 \\
\hline $\mathrm{CaO}$ & 3.5 & 0.82 & SF & \\
\hline $\mathrm{SO} 3$ & 2.5 & 0.87 & Specific gravity & 2.2 \\
\hline L.O.I & 3.5 & 4.10 & Specific surface $\left(\mathrm{m}^{2} / \mathrm{kg}\right)$ & 21000 \\
\hline $\mathrm{CaO}$ (free) & 1.32 & 2.15 & & \\
\hline
\end{tabular}




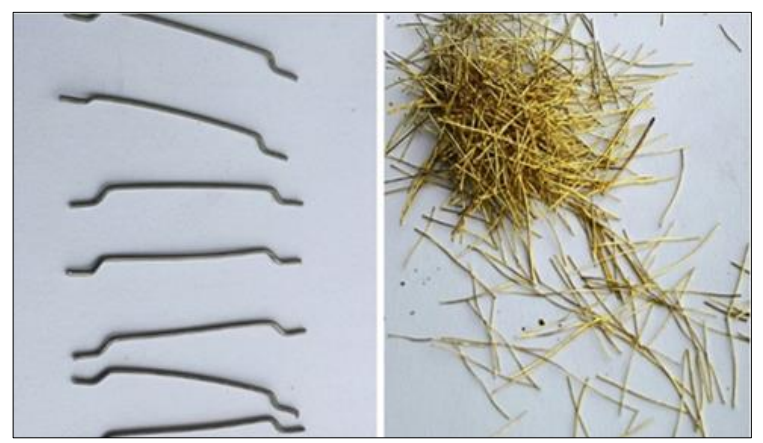

Figure 3. Steel fibres used: hooked end steel fibre and micro steel fibre

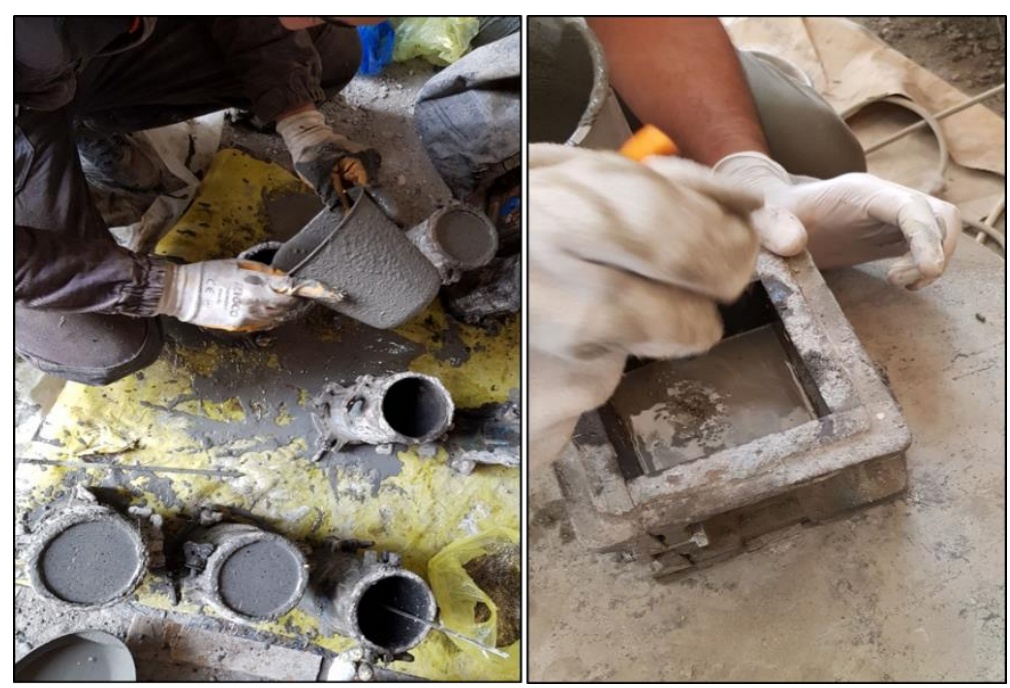

Figure 4. Pouring processes of SIFCON samples

The samples were heated to three temperature levels of $\left(400,600\right.$ and $\left.900{ }^{\circ} \mathrm{C}\right)$ for 2 and 3 hours. For compressive strength, three cubes were tested, and three cylinders for elastic modulus at each temperature level and fire exposure duration from each series. Three samples at room temperature were used as reference samples for each test of each series. Thus, 24 cubes and 24 cylinders of each series were tested.

The fire exposure tests were performed at Babylon University Faculty of Engineering in the laboratory of structural material properties. The dimensions of the manufactured furnace is $1500 \mathrm{~mm}$ length, $1500 \mathrm{~mm}$ width and $1250 \mathrm{~mm}$ height. The thickness of all walls for every side is fixed at $250 \mathrm{~mm}$, the principal structure is built with refractory bricks and mortar and has a small openings for giving suitable burners air, and the cover of the furnace has been made with 8 $\mathrm{mm}$ thick insulating plate to maintain the fire temperature. The primary aim of the furnace chamber is to raise the levels of temperature of the exposure to fire and to keep it constant for the required duration. To control the temperature of fire, the process of heating comprises of the equipment as illustrated in Figure 5. The burners set comprises of group liquefied petroleum gas burners, all burners were connected together in one pipeline as shown in Figure 5.

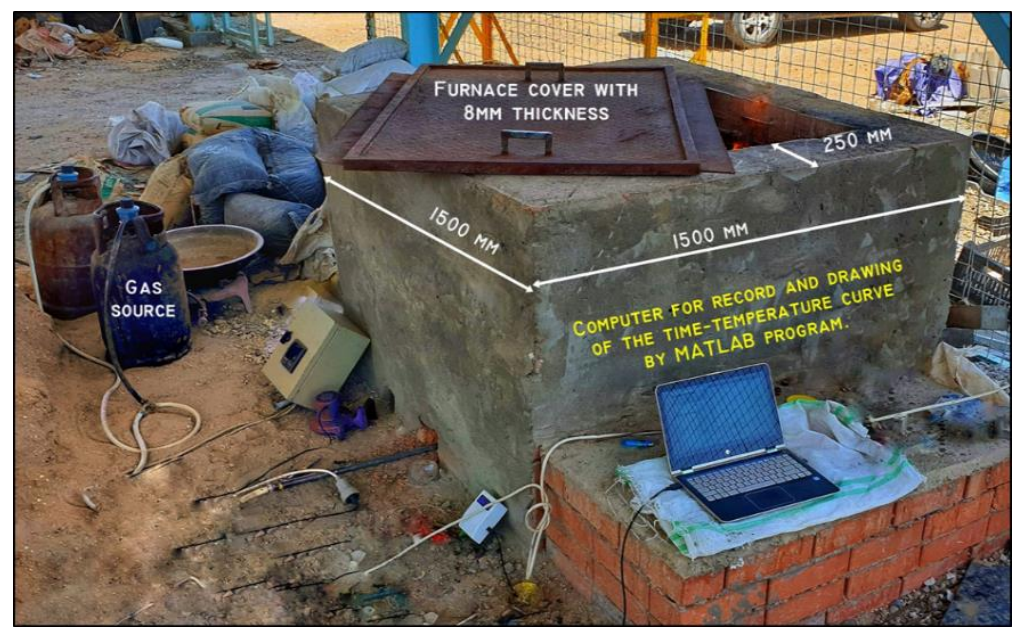

Figure 5. Details of the brick furnace 
In order to control the gas of liquefied petroleum, the electrical gas regulator together with the thermocouples were attached to a digital gauge. The SIFCON samples (for compressive strength and modulus of elasticity) were burned in the furnace according to the standard fire curve recommended of ISO-834 as shown in Figure 6. The first part of fire curve was observed to be similar to that of standard fire curve up to $900{ }^{\circ} \mathrm{C}$. After burning to the specific fire temperature (see part I in Figure 6), columns were held at these maximum temperature for 2 or 3 hours (see part II) at (400, 600 and $900{ }^{\circ} \mathrm{C}$ ). Under laboratory conditions, column specimens were then cooled down. The heating rate of the experimental curve and the maximum temperature fire exposure is less than that of the ISO-834 recommendation, which is a limitation of the equipment available.

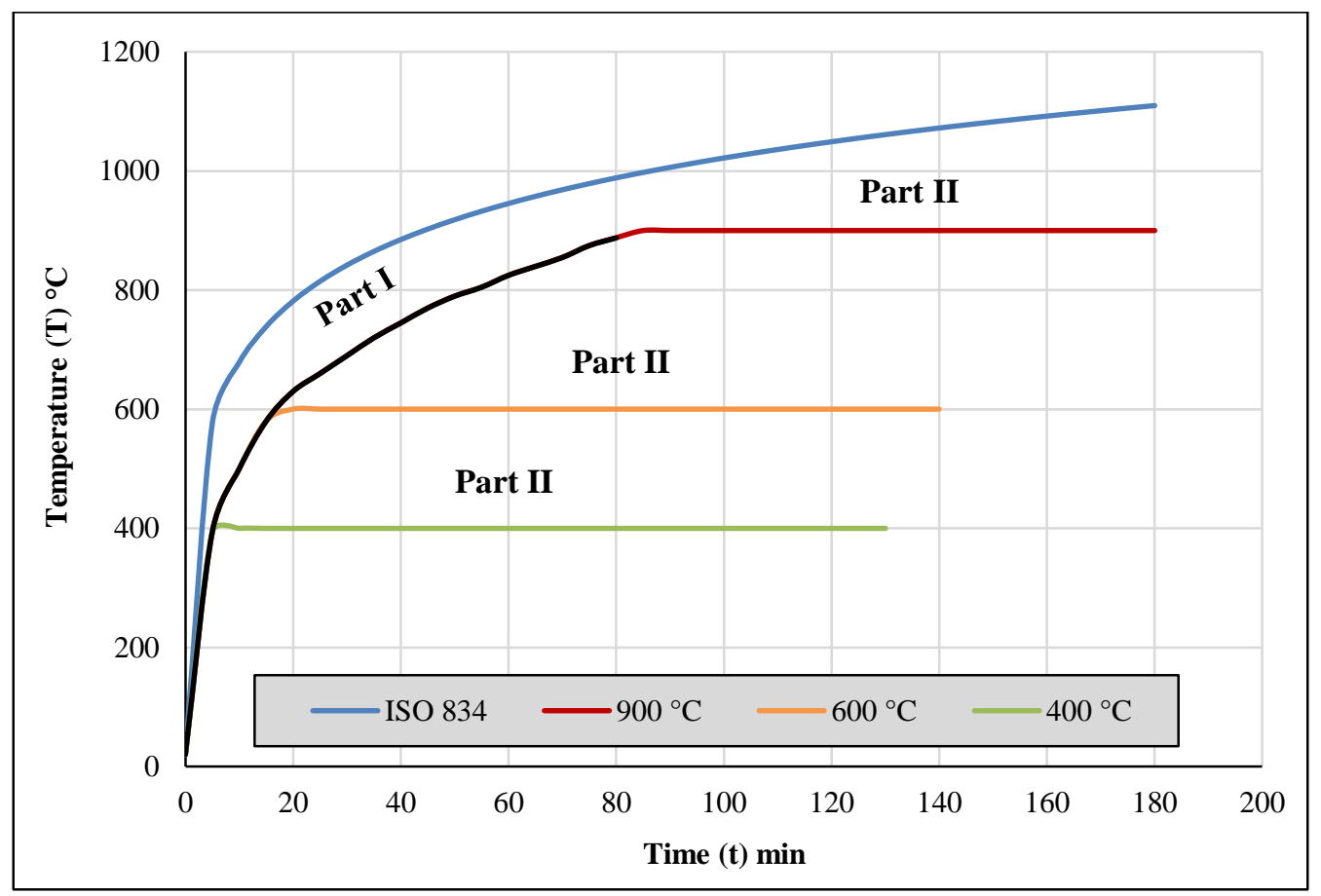

Figure 6. Experimental and ISO-834 Standard recommended temperature-time curves

The real time-temperature curve was programmed by MATLAB program so that the heat thermocouple inside the furnace was connected to the computer to record the temperature values directly with the time. Then at the end of the burning process the temperatures and times data are stored with the final shape of the time-temperature curve on the computer. Figure 7 illustrates an example of the time-temperature curve drawing by MATLAB program.

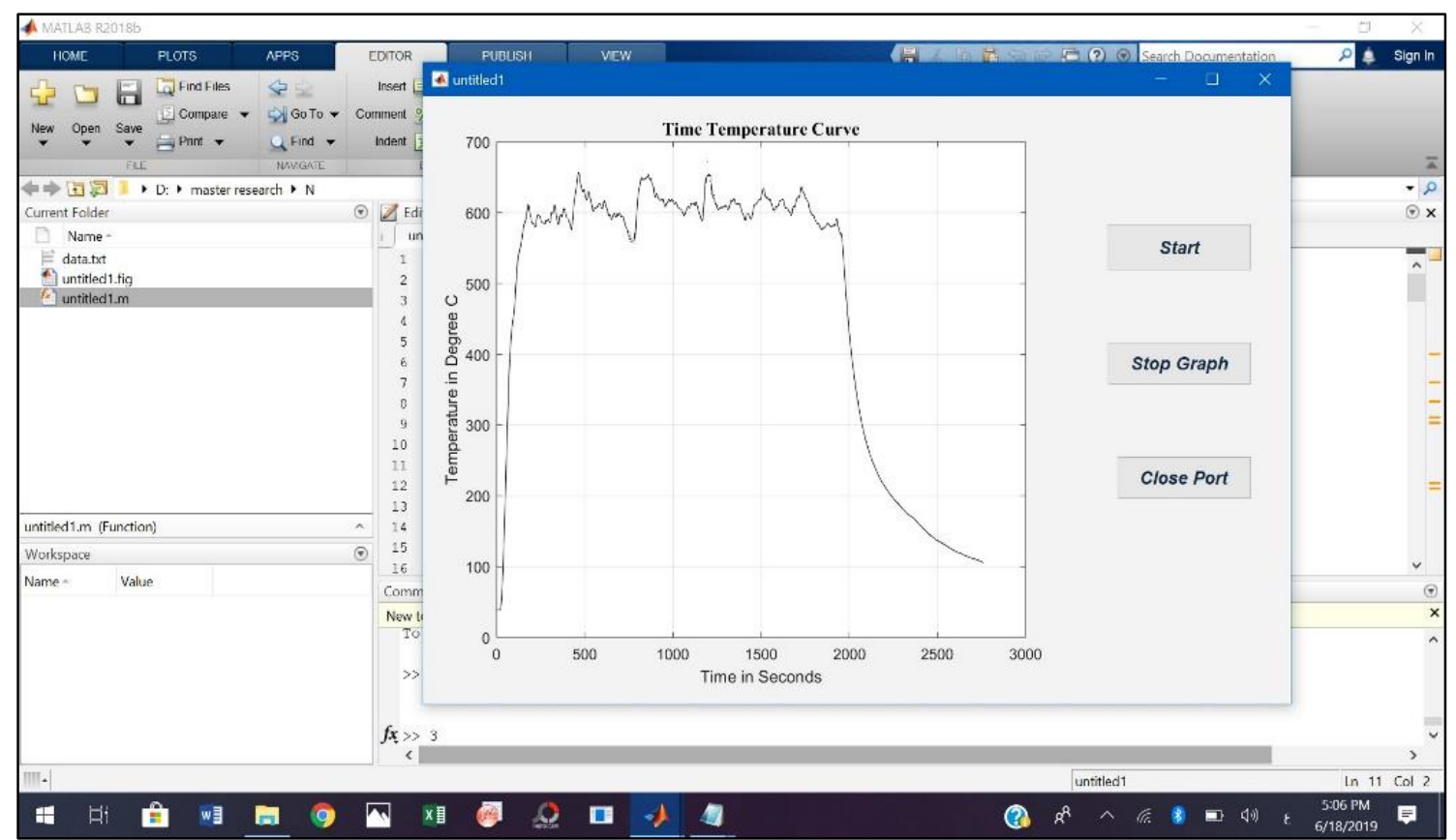

Figure 7. An example for record and drawing of the time-temperature curve by MATLAB program 


\section{Results and Discussion}

In this research, compressive strength and modulus of elasticity of slurry infiltrated fibrous concrete (SIFCON) were investigated both at ordinary temperatures and after exposure to high temperatures.

\subsection{SIFCON Compressive Strength}

Table 3 demonstrates the SIFCON compressive strength before and after burning. In this table, each value reflects the average values collected from the 3 cubes test in order to minimize the anticipated mistake in any measured consequence.

Table 3. Compressive strengths results of SIFCON samples before and after exposure to fire flame

\begin{tabular}{|c|c|c|c|c|c|c|c|}
\hline \multirow{3}{*}{ Age (days) } & \multicolumn{7}{|c|}{ Compressive Strength $f_{\mathrm{cu}}(\mathrm{MPa})$} \\
\hline & \multirow{2}{*}{$25^{\circ} \mathrm{C}$} & \multicolumn{3}{|c|}{2 hr. fire exposure } & \multicolumn{3}{|c|}{3 hr. fire exposure } \\
\hline & & $400^{\circ} \mathrm{C}$ & $600^{\circ} \mathrm{C}$ & $900{ }^{\circ} \mathrm{C}$ & $400{ }^{\circ} \mathrm{C}$ & $600{ }^{\circ} \mathrm{C}$ & $900{ }^{\circ} \mathrm{C}$ \\
\hline 28 & 98.41 & 90.20 & 79.38 & 58.65 & 84.77 & 75.70 & 51.27 \\
\hline $\mathrm{f}_{\mathrm{cu}} / \mathrm{f}_{\mathrm{cu}}\left(\mathrm{T}=25^{\circ} \mathrm{C}\right) \%$ & 100 & 91.6 & 80.6 & 59.6 & 86.1 & 74.9 & 52.1 \\
\hline Change in $\mathrm{f}_{\mathrm{cu}} \%$ & 0 & -8.4 & -19.4 & -40.4 & -13.9 & -25.1 & -47.9 \\
\hline
\end{tabular}

Figure 8 reveals the measured relative residual compressive strengths of SIFCON samples as a function of maximum temperature up to $900{ }^{\circ} \mathrm{C}$. From this Figure, it can be concluded that the drastically reduction of compressive strength took place with increasing temperature above $600{ }^{\circ} \mathrm{C}$. This reduction could be explained by the decomposition of C-S$\mathrm{H}$ and $\mathrm{CH}$ hydrates throughout the range $\left(400-600^{\circ} \mathrm{C}\right)$ resulting in a strength decreasing. Further decline was due to the aggregate phase transformation at $573{ }^{\circ} \mathrm{C}$ from $\alpha$ to $\beta$ phase [11]. In addition, the bond between slurry and steel fibers has worsened deteriorated over $700{ }^{\circ} \mathrm{C}$, owing to different expansion among them. Severe cracking at $900{ }^{\circ} \mathrm{C}$ led in more than $(45 \%)$ loss of compressive strength.

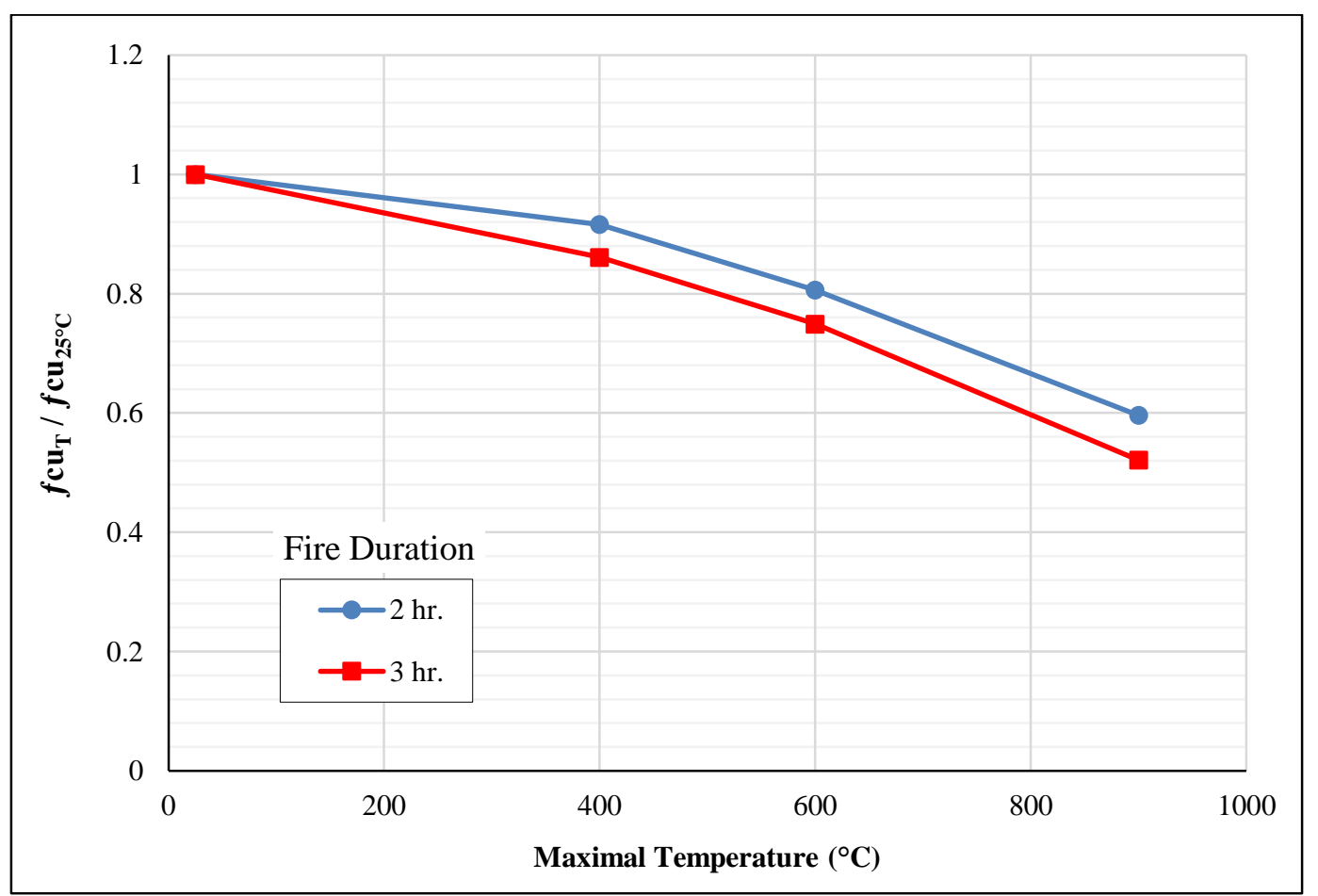

Figure 8. Measured compressive strength as a function of temperature (relative strength values related to those at $25{ }^{\circ} \mathrm{C}$ )

Figure 9 shows the comparison between the residual in compressive strength after exposure to fire flame obtained in this study with the residual in compressive strength of different concrete obtained from different studies as follow: (The results of three hours fire exposure at age of 28 days were compared).

- Fitting model without fiber content for normal strength concrete (NSC) and high strength concrete (HSC) [12].

- High-performance concrete (HPC) fitting model [8]. 
- Steel fiber-reinforced normal strength concrete (SFRC) fitting model [13].

- Experimental results of reactive powder concrete (RPC) [14].

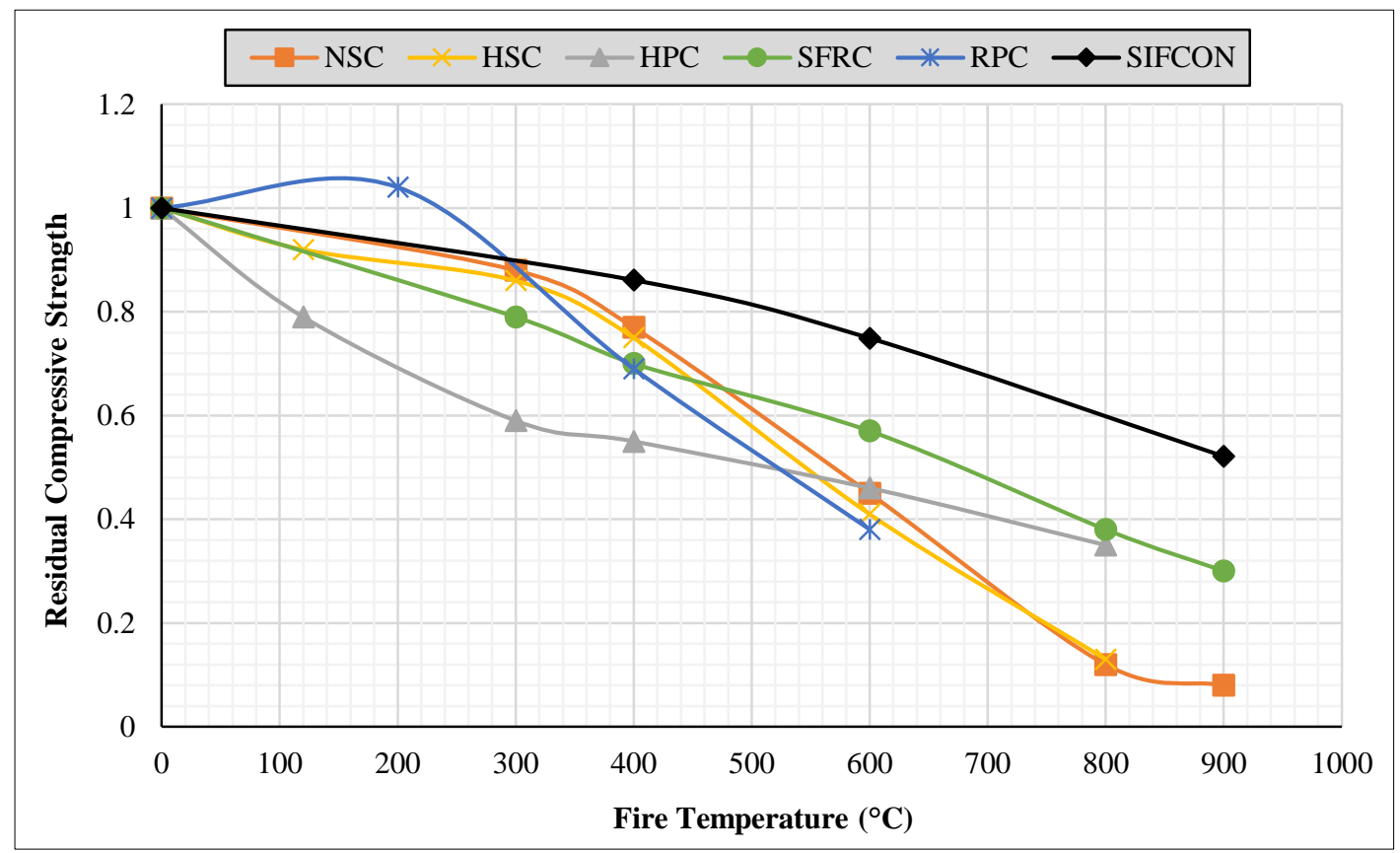

Figure 9. Comparison of compressive strength values at 28 days with other types of concrete for different researchers

From Figure 9, it is evident that SIFCON performs better than other traditional types of concrete due to its superior microstructure and effective role of steel fibres to resist spalling and crack propagation at high temperatures, resulted in improved compressive strength. The results of this research are in good agreement with the SFRC results as reported by Aslani and Samali, (2014) [13].

The appearance of the cube samples after fire flame exposure at various temperature levels and fire durations are demonstrated in Figure 10, the pictures of the fire exposed samples displaying distinct micro cracks appearances without the appearance of spalling at different temperature levels taken by HD digital camera.
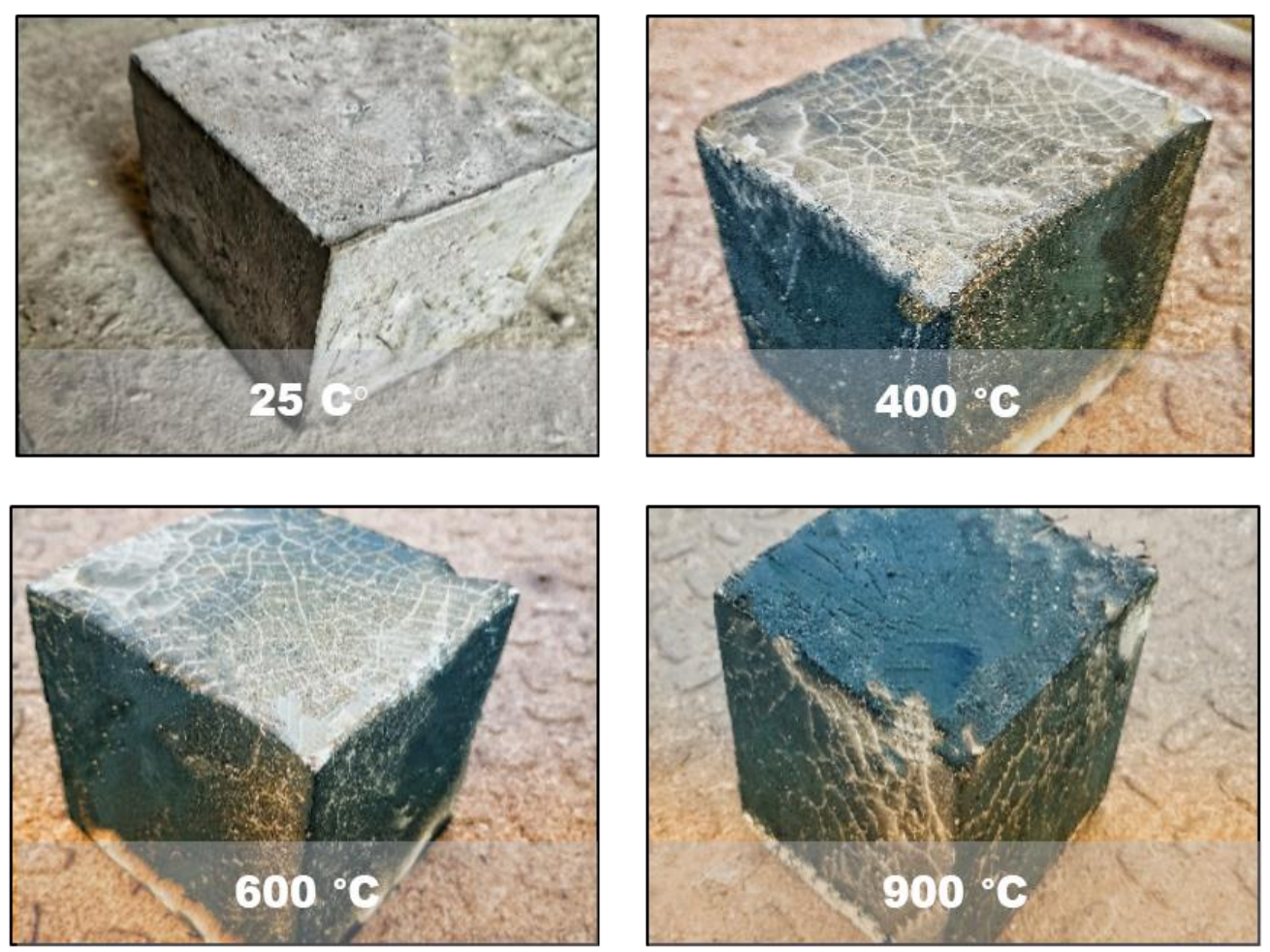

Figure 10. The appearance of cube samples after fire flame exposure for $3 \mathrm{hr}$. fire duration at various fire temperature levels 


\subsection{Static Modulus of Elasticity}

The modulus of elasticity is strongly influenced by the concrete materials and their proportions. An increase in the modulus of elasticity is expected with an increase in compressive strength since the slope of the ascending branch of the stress-strain diagram becomes steeper.

Figure 11 depicts the relationship between modulus of elasticity and fire flame temperature levels for SIFCON samples. From the results of Table 4, it can be observed that the reduction in elastic modulus values at the same fire flame temperatures is more significant than the reduction in compressive strength. Reducing the elastic modulus is due to the breakage of bonds in the cement paste microstructure and the differential movement between the cement paste and the aggregate that occurs when the SIFCON is subjected to high firing temperatures [6].

Table 4. Test values of elastic modulus of SIFCON samples before and after exposure to fire flame

\begin{tabular}{|c|c|c|c|c|c|c|c|}
\hline \multirow{3}{*}{ Age (days) } & \multicolumn{7}{|c|}{ Modulus of Elasticity Ec (GPa) } \\
\hline & \multirow{2}{*}{$25^{\circ} \mathrm{C}$} & \multicolumn{3}{|c|}{$2 \mathrm{hr}$. fire exposure } & \multicolumn{3}{|c|}{$3 \mathrm{hr}$. fire exposure } \\
\hline & & $400{ }^{\circ} \mathrm{C}$ & $600{ }^{\circ} \mathrm{C}$ & $900{ }^{\circ} \mathrm{C}$ & $400{ }^{\circ} \mathrm{C}$ & $600{ }^{\circ} \mathrm{C}$ & $900{ }^{\circ} \mathrm{C}$ \\
\hline 28 & 28.77 & 20.59 & 16.37 & 9.81 & 17.9 & 13.40 & 8.80 \\
\hline $\mathrm{Ec} / \mathrm{Ec}\left(\mathrm{T}=25^{\circ} \mathrm{C}\right) \%$ & 100 & 71.6 & 56.9 & 34.1 & 62.3 & 46.5 & 30.6 \\
\hline Change in Ec \% & 0 & -28.4 & -43.1 & -65.9 & -37.7 & -53.5 & -69.4 \\
\hline
\end{tabular}

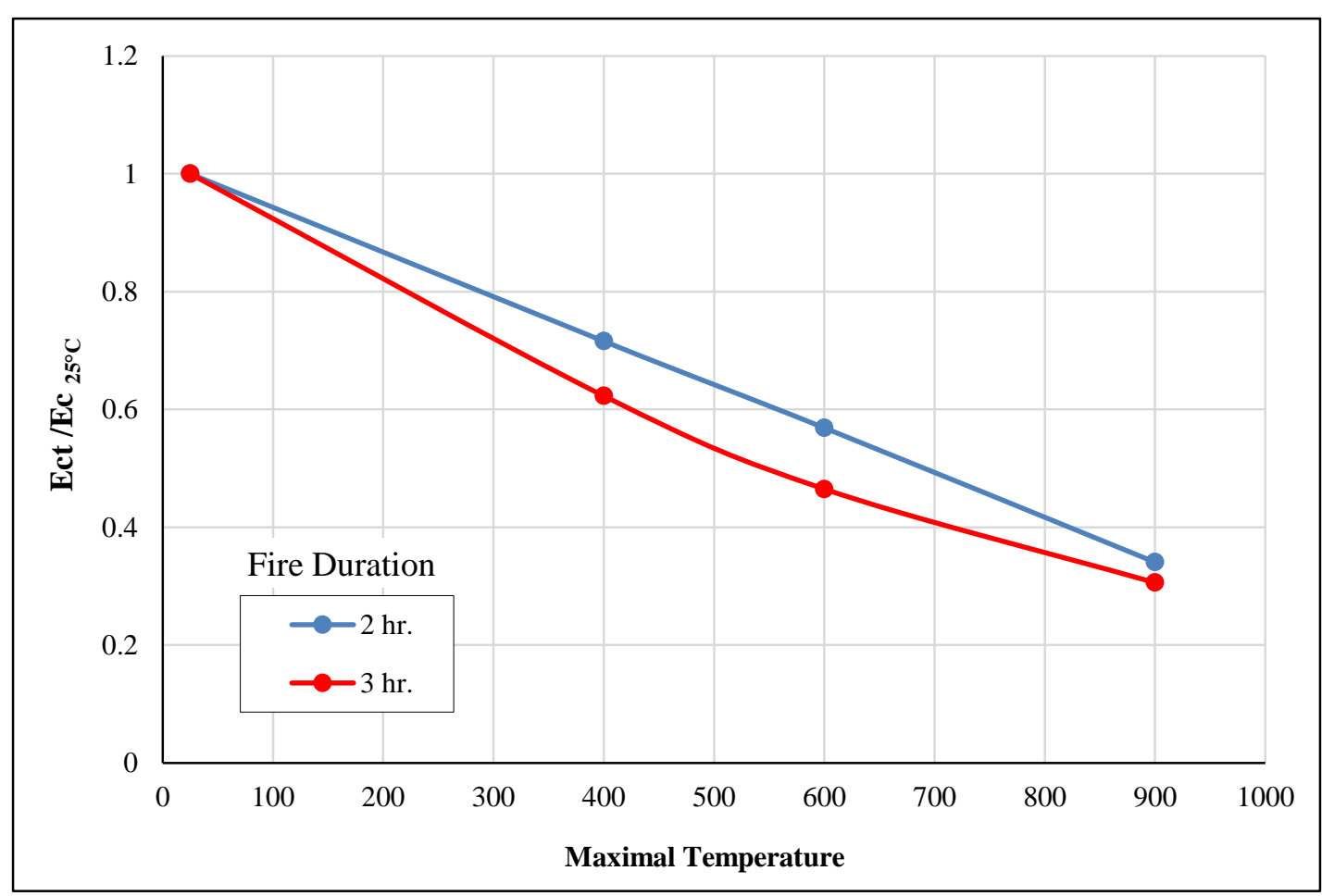

Figure 11. Fire flame effect of on elastic modulus of SIFCON samples

In Figure 12, the ratio of modulus of elasticity at elevated temperature to corresponding unheated modulus of elasticity has been plotted along with those computed from experimental values of other type of concrete obtained from relevant literature. (The results of three hours fire exposure at age of 28 days were compared).

- Fitting model for normal strength concrete (NSC) [12].

- Fitting model for plain high performance concrete (HPC) [8].

- Fitting model for steel fiber-reinforced normal strength concrete (SFRC) [13].

- Ultra-high strength concrete (UHSC) experimental results [15].

- Experimental results of reactive powder concrete (RPC) [14]. 


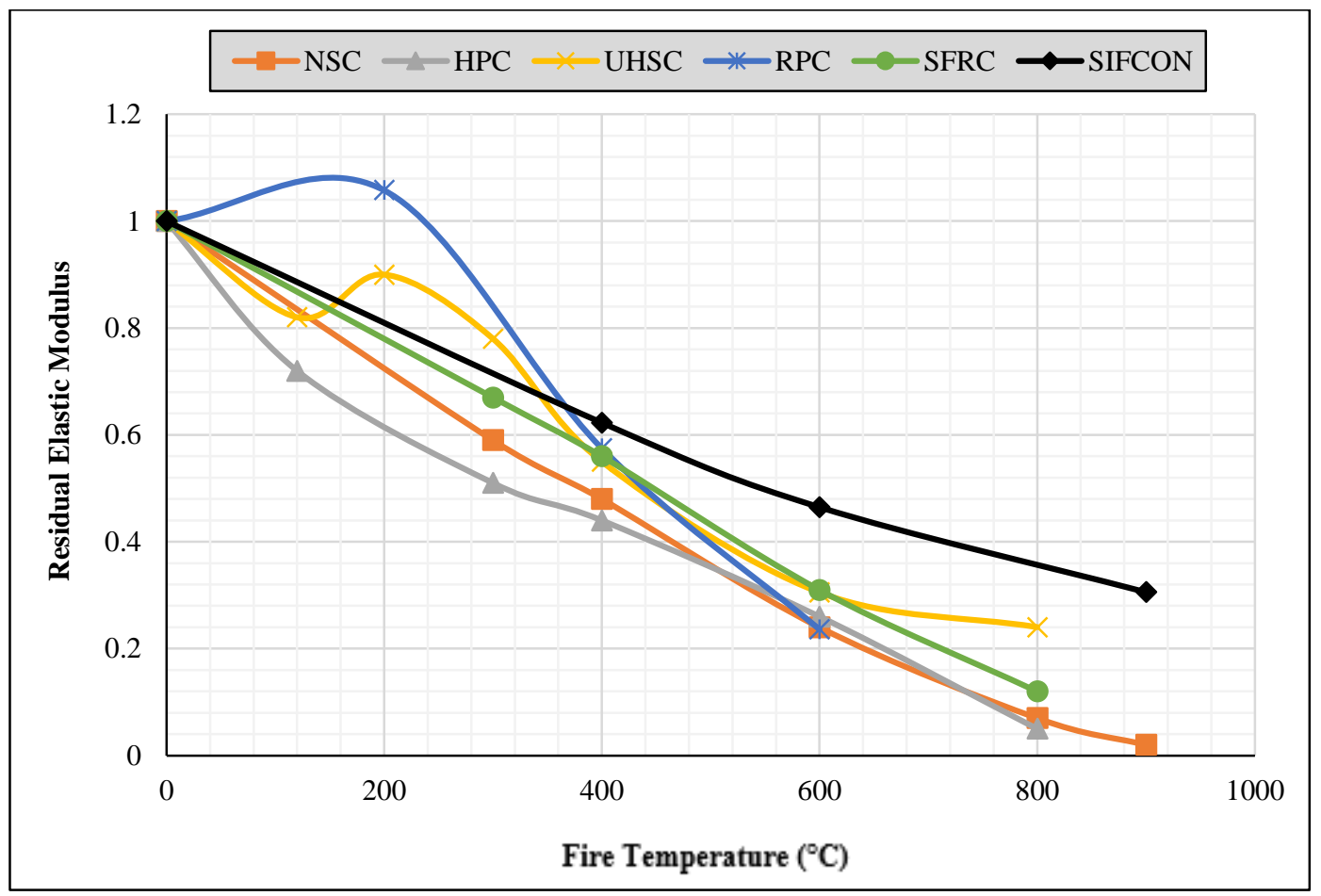

Figure 12. Comparison of elastic modulus values at 28 days with other types of concrete for different researchers

It is evident from Figure 12 that the elastic modulus of SIFCON samples obtained from the experimental work of the present study is comparable to that of SFRC up to $400^{\circ} \mathrm{C}$, but at higher temperatures, SIFCON performs better due to the interlocking action of the fibres, where crack propagation has been controlled and crack growth has been inhibited. In addition to the effect of steel fibre on the increase in the weight of the specimens, and consequently the increase in the elastic modulus and the effective role of high content of steel fibres in resisting spalling and cracking at high temperatures.

\section{Conclusions}

The following conclusions can be drawn on the basis of the test results of this study and within the limitations of the test parameters:

- The fire exposed SIFCON samples maintained its shape after burning and no evidence of spalling was found.

- The drastically reduction of compressive strength and elastic modulus took place with increasing temperature above $600{ }^{\circ} \mathrm{C}$ due to the decomposition of $\mathrm{C}-\mathrm{S}-\mathrm{H}$ and $\mathrm{CH}$ hydrates.

- Results show that the decrease in elastic modulus values at the same fire flame temperatures is more significant than in compressive strength.

- The residual compressive strength and elastic modulus at $900{ }^{\circ} \mathrm{C}$ was in the range of $(52.1 \%$ to $59.6 \%)$ and (30.6\% to $34.1 \%$ ) respectively.

- By comparison the results of SIFCON residual compressive strength and elastic modulus after fire flame exposure with the results calculated from experimental values of other type of concrete collected from many other studies. It's clear that SIFCON performs better than other types of concrete at high temperatures.

\section{Acknowledgement}

The authors wish to express their gratitude and sincere appreciation to the head and staff of Civil Engineering Department in Babylon University. I would like also to express my special appreciation to staff of construction materials laboratory at the civil engineering department for presenting all the facilities to finish this work.

\section{Conflicts of Interest}

The authors declare no conflict of interest. 


\section{References}

[1] Lankard, David R. "Slurry Infiltrated Fiber Concrete (SIFCON): Properties and Applications." MRS Proceedings 42 (1984). doi:10.1557/proc-42-277.

[2] Manolia, A A, A S Shakir, and J F Qais. "The Effect of Fiber and Mortar Type on the Freezing and Thawing Resistance of Slurry Infiltrated Fiber Concrete (SIFCON).” IOP Conference Series: Materials Science and Engineering 454 (December 12, 2018): 012142. doi:10.1088/1757-899x/454/1/012142.

[3] Rao, H. Sudarsana, Vaishali G. Ghorpade, N.V. Ramana, and K. Gnaneswar. "Response of SIFCON Two-Way Slabs under Impact Loading." International Journal of Impact Engineering 37, no. 4 (April 2010): 452-458. doi:10.1016/j.ijimpeng.2009.06.003.

[4] Shanthini, D., and E. K. Mohanraj. "Mechanical behavior of SIFCON beams." International Journal of Science and Engineering Research (IJOSER) 3, no. 3 (2015).

[5] Salih, Shakir Ahmed, Qais Jwad Frayyeh, and Manolia Abed Al-wahab Ali. "Flexural Behavior of Slurry Infiltrated Fiber Concrete (SIFCON) Containing Supplementary Cementitious Materials." Journal of Engineering and Sustainable Development 22, no. 02 Part-3 (2019): 35-48.

[6] Lankard, David R., and Daniel H. Lease. "Highly reinforced precast monolithic refractories." Am. Ceram. Soc. Bull.;(United States) 61, no. 7 (1982): 728-732.

[7] Kadhum, Mohammed Mansour, and Bushra Salman Mankhi. "Behavior of Reactive Powder Concrete Columns with or without Steel Ties.”, 2015.

[8] Khaliq, Wasim, and Venkatesh Kodur. "Thermal and Mechanical Properties of Fiber Reinforced High Performance SelfConsolidating Concrete at Elevated Temperatures.” Cement and Concrete Research 41, no. 11 (November 2011): $1112-1122$. doi:10.1016/j.cemconres.2011.06.012.

[9] Beglarigale, Ahsanollah, Çağlar Yalçınkaya, Hüseyin Yiğiter, and Halit Yazıcı. "Flexural Performance of SIFCON Composites Subjected to High Temperature." Construction and Building Materials 104 (February 2016): 99-108. doi:10.1016/j.conbuildmat.2015.12.034.

[10] Al-Owaisy, Sallal Rashid, and Muhaned A. Shallal. "Strength and elasticity of steel fiber reinforced concrete at high temperatures." Journal of Engineering and Sustainable Development 11, no. 2 (2007): 125-133.

[11] Abrams, Melvin S. "Compressive strength of concrete at temperatures to 1600F." Temperature and Concrete 25 (1971): $33-58$.

[12] Aslani, Farhad, and Morteza Bastami. "Constitutive relationships for normal-and high-strength concrete at elevated temperatures." ACI Materials Journal 108, no. 4 (2011): 355.

[13] Aslani, Farhad, and Bijan Samali. "Constitutive Relationships for Steel Fibre Reinforced Concrete at Elevated Temperatures." Fire Technology 50, no. 5 (January 16, 2013): 1249-1268. doi:10.1007/s10694-012-0322-5.

[14] Abdulraheem, Mustafa S., and Mohammed M. Kadhum. "Experimental and Numerical Study on Post-Fire Behaviour of Concentrically Loaded Reinforced Reactive Powder Concrete Columns." Construction and Building Materials 168 (April 2018): 877-892. doi:10.1016/j.conbuildmat.2018.02.123.

[15] Liew, J. Y. R., and D. X. Xiong. "Experimental investigation on tubular columns infilled with ultra-high strength concrete." In Tubular Structures XIII-Proceedings of the 13th International Symposium on Tubular Structures (2010): 637-645. 